Academic Platform Journal of Engineering and Science

journal homepage: http://apjes.com/

\title{
Fluidized Electrooxidation Process Using Three-Dimensional Electrode for Decolorization of Reactive Blue 221
}

\author{
${ }^{* 1}$ Kubra Ulucan-Altuntas, \\ ${ }^{1}$ Yildiz Technical University, Department of Environmental Engineering, Istanbul, Turkey, \\ kulucan@yildiz.edu.tr, ic \\ Research Paper \\ Arrival Date: 20.08 .2020 \\ Accepted Date: 21.11.2020
}

\begin{abstract}
With the addition of a particle electrode to the two-dimensional electrooxidation process using Pt coated titanium electrodes, the decolorization of reactive blue 221, one of the reactive dyes that are frequently used in the textile industry, has been studied. Experimental matrix was determined according to Box Behnken Design and evaluated with ANOVA results and surface plots. The selected independent variables were selected as color concentration, current density and time. Accordingly, it has been determined that the optimum condition $20 \mathrm{~mA} / \mathrm{cm} 2$ of current density, $20.5 \mathrm{~min}$ of reaction time for the sample containing 60.6 $\mathrm{mg} / \mathrm{L}$ color concentration. In addition, a separate study was carried out to determine the accuracy of the model with the experimental results, and it was compared with the adsorption and 2D electrooxidation process. Accordingly, it was obtained that the activated carbon in the 3D process, other than adsorption, acts as a carbocatalyst. The results of the study were evaluated according to Langmuir and Freundlich isotherms, pseudo-first-order and pseudo-second-order kinetic models, and it was found to be compatible with Langmuir and pseudo-second-order kinetic model. Maximum adsorption capacity was calculated as 5.93 $\mathrm{mg} / \mathrm{g}$ from Langmuir isotherm.
\end{abstract}

Keywords: Particle Electrode, Three-dimensional electrode, Electrochemical processes, Electrooxidation, Decolorization

\section{INTRODUCTION}

The textile industry containing dye material creates an ecological problem by preventing the passage of sunlight in case of discharge of wastewater. Textile industry wastewater differs in terms of technologies used in which reactive dyes often used [1]. In recent years, electrochemical treatment methods have made great progress in wastewater treatment as it is both highly efficient and environmentally friendly than conventional treatment processes. Except from advanced oxidation processes such as ozonation [1], photocatalytic degradation [2] and Fenton [3] processes; electrocoagulation, electro-Fenton and electrooxidation methods have been frequently investigated for the treatment of textile wastewater containing dye materials [4 - 6]. However, there are some limitations in the application of these two-dimensional electrodes, such as the short life of the electrode used, the low current efficiency due to low conductivity [7]. In two-dimensional electrode (2D) processes, in order to eliminate these disadvantages, it can be eliminated by using three-dimensional electrodes (3D) using activated carbon or metal particles [8]. Significant increases in removal efficiencies are observed due to its large specific surface areas, adsorption and also catalytic reactions.

Particles placed between the anode and cathode which are not in direct contact with electricity act as a particle electrode in the 3D electrochemical process. The adsorption of the pollutant material is inevitable because the particulate electrode has high specific surface area. However, since it will be in the electric field, one side of the particles will be charged as positively and the other side as negatively [7, 9], [10]. This formed electron adsorption allows them to exhibit catalytic properties. In the 2D electrooxidation process, oxidation takes place by transferring electrons on the anode and/or producing active species such as the hydroxyl radical electrically. Particle electrodes used in 3D electrooxidation processes act like micro electrolytic cells [7]. Except from the oxidation occurred on anode, active species can be produced directly or indirectly on the particle which contribute to increase degradation efficiency $[9,10]$. It is mentioned in the literature that activated carbon converts $\mathrm{H}_{2} \mathrm{O}_{2}$ to hydroxyl radical and can be used as a carbocatalyst [11-13].

The most commonly used dyes in the textile industry are reactive dyes, and they are the main source of color in textile wastewater. In this study, the effect of 3D electrooxidation process was investigated in reactive blue 221 anionic dye removal as a pollutant source of textile wastewater. The studies on 3D electrooxidation processes were mostly researched for fixed bed particle electrode conversely, the fluidized bed reactor for 3D electrooxidation process is design for decolorization. In this process, activated carbon

${ }^{*}$ Corresponding Author: Yildiz Technical University, Department of Environmental Engineering, Istanbul, Turkey, kulucan@yildiz.edu.tr, +90 2123835399 
was used as the particle electrode, and Ti/Pt and Ti electrodes were used as the anode and cathode, respectively.

\section{MATERIALS AND METHOD}

\subsection{Materials}

Experiments were carried out using Reactive Blue 221 (RB), which its trade name and CAS registry number are Strazol Reactive Blue GBRF and 93051-41-3, respectively. The chemical structure of RB is given in Figure 1. Sodium sulfate and activated carbon were purchased from Merck and Sigma Aldrich, respectively.

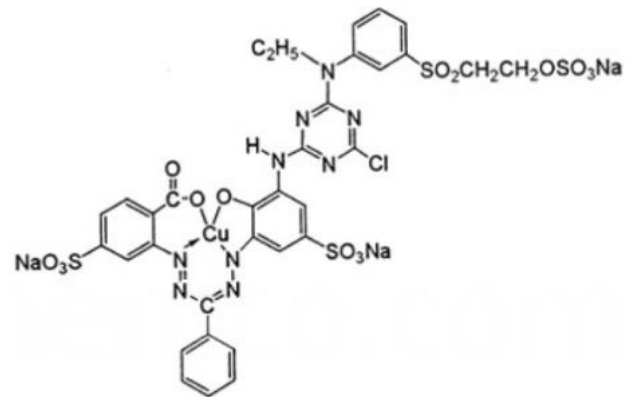

Figure 1. Chemical Structure of Reactive Blue 221

\subsection{Experimental Studies}

The experiments were conducted in a $100 \mathrm{~mL}$ volume reactor which is shown in Figure 2. 3D electrooxidation process was established with $\mathrm{Ti} / \mathrm{Pt}$ anode electrodes and $\mathrm{Ti}$ cathode electrode, which were placed with a $5 \mathrm{~cm}$ electrode-gap. AC was added in $500 \mathrm{mg} / \mathrm{L}$ concentration in the solution and to obtain fluidized characteristic inside the reactor, the solution was mixed at constant rate by WiseStir brand magnetic stirrer plate (MSH-20A model). Current density was applied with GW brand DC power supply (GPC-3060i model). For conductivity $40 \mathrm{mM} \mathrm{Na}_{2} \mathrm{SO}_{4}$ was added.

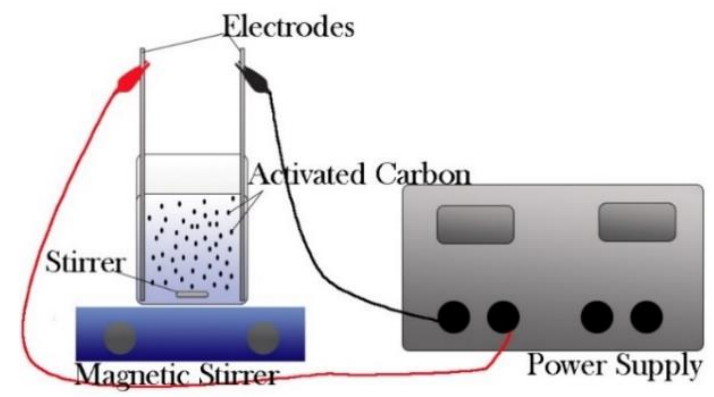

Figure 2. Experimental set-up

\subsection{Response Surface Methodology}

The design of experiment (DoE) is the advanced statistical tool that demonstrates mathematical models between inputs and outputs of processes [1]. Owing to the DoE, the factorial approach can identify critical factors in the process, with less substance consumption in research. Box-Behnken design (BBD), one of the response surface methods used as an alternative to factorial techniques, was designed in 1960 by
George Box and Donald Behnken. The dots placed on the edges, center, and center of the cubic design in the BoxBehnken design are coded as $-1,0,+1$. In this study, these 3 factors are the independent variables chosen for 3 level design, color concentration, current density and time. The study matrix is given in Table 1 . According to Table 1, the three independent variables were selected as Color concentration $\left(\mathrm{X}_{1}\right)$, current density $\left(\mathrm{X}_{2}\right)$ and time $\left(\mathrm{X}_{3}\right)$. Volume of the sample was $80 \mathrm{~mL}$. $\mathrm{pH}$ and temperature of the sample was kept constant at $\mathrm{pH} 6$ and $25^{\circ} \mathrm{C}$, respectively [14]. The activated carbon concentration in the reactor was selected as $500 \mathrm{mg} / \mathrm{L}$ to eliminate high adsorption rates.

Table 1. Levels of independent variables

\begin{tabular}{|l|c|c|c|c|}
\hline \multicolumn{2}{|r|}{ Levels } & & & \\
Independent Variables & $\mathrm{X}_{1}$ & -1 & 0 & 1 \\
\hline Color Concentration, mg/L & 20 & 60 & 100 \\
\hline Current Density, $\mathrm{mA} / \mathrm{cm}^{2}$ & $\mathrm{X}_{2}$ & 10 & 20 & 30 \\
\hline Time, min & $\mathrm{X}_{3}$ & 5 & 15 & 25 \\
\hline
\end{tabular}

According to Table 1, experimental sets given in Table 2 was conducted, and accordingly second order model was analyzed via ANOVA results based on the Eq (1):

$y=\beta_{0}+\sum_{i=1}^{k} \beta_{i} X_{i}+\sum_{i=1}^{k} \beta_{i i} X_{i}^{2}+\sum_{i=1}^{k} \sum_{j=i+1}^{k} \beta_{i j} X_{i} X_{j}+\varepsilon$

In Eq (1) $\mathrm{Y}$ is the response which is dependent variable, $X_{i}$ and $X j$ are codded independent variables, while $\beta_{0}$ represents intercept; $\beta_{\mathrm{i}}, \beta_{\mathrm{ii}}$ and $\beta_{\mathrm{ij}}$ represent the coefficients of linear, quadratic and interaction terms, respectively. To analyse ANOVA and optimization, Excel program was used. The removal efficiencies are considered as response in BBD and were calculated by Eq (2).

$E, \%=\frac{\left(C_{0}-C_{e}\right)}{C_{0}} x 100$

\subsection{Isotherm and Kinetic Modeling}

Adsorption isotherms and kinetic models were used to evaluate the adsorption properties of the particular electrodes used in the $3 \mathrm{D}$ electrooxidation process. In case the temperature is constant, adsorption capacity can be calculated by Equation (3):

$q_{e}=\frac{\left(C_{0}-C_{e}\right) \cdot V}{m}$

In Equation (3), $\mathrm{q}_{\mathrm{e}}$ is adsorption capacity in $\mathrm{mg} / \mathrm{g}, \mathrm{C}_{\mathrm{i}}$ and $\mathrm{C}_{\mathrm{e}}$ are represented for initial and effluent color concentration in $\mathrm{mg} / \mathrm{L}$, respectively. $\mathrm{V}$ and $\mathrm{m}$ are sample volume in 1 and $\mathrm{AC}$ amount in $\mathrm{g}$, respectively.

The suitability of isotherm models was considered. The commonly used isotherms Freundlich and Langmuir isotherm can be expressed as in Equation (4) and (5), respectively.

$q_{e}=K_{F} C_{e}^{\frac{1}{n}}$ 
$q_{e}=\frac{K_{L} q_{\max } C_{e}}{1+K_{L} C_{e}}$

where, $\mathrm{q}_{\max }$ is representing maximum adsorption capacity, $1 / n$ is representing Freundlich density parameter, $\mathrm{K}_{\mathrm{F}}$ and $\mathrm{K}_{\mathrm{L}}$ are representing capacity coefficients for Freundlich and Langmuir, respectively.

Kinetic modelling is considered for Pseudo-first-order and Pseudo-second-order kinetic model, which can be expressed in Equation (6) and Equation (7), respectively.

$\frac{d q_{t}}{d q}=k_{1} *\left(q_{e}-q_{t}\right)$

$\frac{t}{q t}=\frac{1}{k_{2} * q_{e}^{2}}+\frac{t}{q_{e}}$

where, $\mathrm{k}_{1}$ and $\mathrm{k}_{2}(1 / \mathrm{min})$ are kinetic coefficient for pseudofirst-order kinetic and pseudo-second-order kinetic modelling, respectively. $\mathrm{q}_{\mathrm{e}}$ and $\mathrm{q}_{\mathrm{t}}$ are representing the adsorption capacities in equilibrium and at time, respectively.

\section{RESULTS AND DISCUSSION}

While the most of the studies on 3D electrooxidation processes were researched with particle electrode in the fixed bed, the effect of the reactor set to be the fluidized bed on the color removal was investigated. For this purpose, BBD design with independent variables color concentration, current density and time was applied. The BBD experimental design concept and the results obtained are presented in Table 2 .

ANOVA analysis of the study was applied via the Excel program, and the results were shown in Table 3 . The significantly lower $\mathrm{P}$ value $(6.57 \mathrm{E}-04)$ than the $\mathrm{F}$ value (32.42) shows that the applied model is statistically significant. Furthermore, the regression coefficient of the model is high as 0.992 which is a sign of satisfactory prediction. Besides, a 95\% confidence interval was used to determine whether the independent variables were significant. The importance of the independent variables is presented in Table 3 according to the P-value. If P-value is 0.05 and below, the independent variables are considered as effective. If it is much lower than $<0.0001$, that variable is accepted as the most significant variable and those which are above 0.05 value were not found effective. According to this information, the most significant and effective independent parameter was determined as color concentration. As stated by P-values, all independent variables are detected as effective. The coefficients also give the information of the effectiveness. While the linear coefficient of time was much lower, the quadratic coefficient of time was high. Time can take into consideration as the second effective variable. Coefficients also show how the parameter affects whether it is positive or negative. The negative coefficient of the color concentration indicates that efficiency will decrease with the increase in color concentration. As the variables of time and current density are positive, their effects will be positive. In the light of these information, the Equation (8) can express the model.

$y=99.18-11.821 . x_{1}+6.306 x_{2}+7.835 x_{3}+$
$7.940 x_{1} x_{2}+12.012 x_{1} x_{3}-10.60 x_{1}^{2}-11.248 x_{3}^{2}$

Table 2. Applied BBD matrix for the decolorization

\begin{tabular}{|c|c|c|c|c|}
\hline \multirow{2}{*}{ Runs } & $\begin{array}{c}\text { Color } \\
\text { Concentration }\end{array}$ & $\begin{array}{c}\text { Current } \\
\text { Density }\end{array}$ & $\begin{array}{c}\text { Time } \\
X_{1}\end{array}$ & $\begin{array}{c}\text { Removal } \\
\text { Efficiency, \% }\end{array}$ \\
\hline 1 & -1 & -1 & 0 & 99.97 \\
\hline 2 & 1 & -1 & 0 & 66.65 \\
\hline 3 & -1 & 1 & 0 & 98.54 \\
\hline 4 & 1 & 1 & 0 & 97.98 \\
\hline 5 & -1 & 0 & -1 & 95.54 \\
\hline 6 & 1 & 0 & -1 & 45.67 \\
\hline 7 & -1 & 0 & 1 & 87.97 \\
\hline 8 & 1 & 0 & 1 & 83.15 \\
\hline 9 & 0 & -1 & -1 & 78.34 \\
\hline 10 & 0 & 1 & -1 & 88.55 \\
\hline 11 & 0 & -1 & 1 & 96.66 \\
\hline 12 & 0 & 1 & 1 & 100 \\
\hline 13 & 0 & 0 & 0 & 99.34 \\
\hline 14 & 0 & 0 & 0 & 99.21 \\
\hline 15 & 0 & 0 & 0 & 98.99 \\
\hline
\end{tabular}

Table 3. ANOVA results of BBD design

\begin{tabular}{|l|c|c|c|c|c|}
\hline & $d f$ & $S S$ & $M S$ & $F$ & Signif. $F$ \\
\hline Regression & 9 & 3629.27 & 403.25 & 32.43 & $6.57 \mathrm{E}-04$ \\
\hline Residual & 5 & 62.18 & 12.44 & & \\
\hline Total & 14 & 3691.45 & & & \\
\hline \hline & Coef. & Stnd. Err. & t Stat & P-value & Importance \\
\hline Inter. & 99.18 & 2.036 & 48.713 & $6.9 \mathrm{E}-08$ & - \\
\hline $\mathrm{X}_{1}$ & -11.821 & 1.247 & -9.481 & $2.2 \mathrm{E}-04$ & Very Signif. \\
\hline $\mathrm{X}_{2}$ & 6.306 & 1.247 & 5.058 & 0.004 & Signif. \\
\hline $\mathrm{X}_{3}$ & 7.835 & 1.247 & 6.284 & 0.001 & Signif. \\
\hline $\mathrm{X}_{1} \mathrm{X}_{2}$ & 7.940 & 1.763 & 4.503 & 0.006 & Signif. \\
\hline $\mathrm{X}_{1} \mathrm{X}_{3}$ & 12.012 & 1.763 & 6.813 & 0.001 & Signif. \\
\hline $\mathrm{X}_{2} \mathrm{X}_{3}$ & -2.218 & 1.763 & -1.258 & 0.264 & - \\
\hline $\mathrm{X}_{1}{ }^{2}$ & -10.600 & 1.835 & -5.776 & 0.002 & Signif. \\
\hline $\mathrm{X}_{2}{ }^{2}$ & 1.455 & 1.835 & 0.793 & 0.464 & - \\
\hline $\mathrm{X}_{3}{ }^{2}$ & -11.248 & 1.835 & -6.129 & 0.002 & Signif. \\
\hline $\mathrm{R}^{2} 0.992-\mathrm{R}_{\text {adj }}{ }^{2} 0.952$ & & & \\
\hline
\end{tabular}

3D surface plot graphs obtained from the STATISTICS program were given in Figure 3. The effect of color concentration and time on removal efficiency was shown in Figure 3.a. It can be seen that removal efficiency decreases when the color concentration increases. Accordingly, in cases where the color concentration is below $60 \mathrm{mg} / \mathrm{L}$ and 
the time is more than 15 minutes, the removal efficiency will be $99 \%$ and above. The effect of current density and color concentration on removal efficiency can be seen in figure 3.b. When these two independent variables are compared, it can be concluded that the effect of color concentration is higher than current density. The effect of current density is low when the color concentration is lower than $60 \mathrm{mg} / \mathrm{L}$. However, the removal efficiency increases from $60 \%$ to $92 \%$ with the increment on current density when color concentration is $100 \mathrm{mg} / \mathrm{L}$. In addition, when time and current density variables are compared in Figure 3.c, it can be concluded that time is more effective than current density. These results are similar to ANOVA results and comments. Optimum conditions can be seen in Table 4. According to BBD model, in order to remove $60.6 \mathrm{mg} / \mathrm{L}$ completely, 20 $\mathrm{mA} / \mathrm{cm}^{2}$ of current density and $20.5 \mathrm{~min}$ of reaction time is required. To see the accuracy of the model and to make a comparison with the $2 \mathrm{D}$ process, a study was conducted with the highest initial color concentration of $100 \mathrm{mg} / \mathrm{L}$ and the current density was set to $20 \mathrm{~mA} / \mathrm{cm}^{2}$ which is determined as optimum value. The results of this study, where time is chosen as a variable, can be seen in Figure 4. The experimental results are found to be in $95 \%$ confidence interval based on BBD model.

Table 4. Optimization results

\begin{tabular}{|l|l|l|l|}
\hline \multicolumn{2}{|l|}{ Independent Variable } & Levels & Actual Values \\
\hline $\begin{array}{l}\text { Color } \\
\text { Concentration }\end{array}$ & $\mathrm{X}_{1}$ & 0.014 & $60.6 \mathrm{mg} / \mathrm{L}$ \\
\hline $\begin{array}{l}\text { Current } \\
\text { Density }\end{array}$ & $\mathrm{X}_{2}$ & 0 & $20 \mathrm{~mA} / \mathrm{cm}^{2}$ \\
\hline Time & $\mathrm{X}_{3}$ & 0.553 & $20.5 \mathrm{~min}$ \\
\hline
\end{tabular}

The effect of particle electrode can be seen in Figure 4. The adsorption of activated carbon was also considered and detected as stabilized at approximately $10 \%$ of removal efficiency during the experiments. While adsorption was at $10 \%$, the average of the difference between 2D and 3D processes was $19 \%$. This shows that activated carbon acted as adsorbent and also carbocatalyst. Similar results were also obtained in literature [12, 13]. Adsorption capacity was calculated as 1.89 and $13.98 \mathrm{mg} / \mathrm{g}$ for adsorption of activated carbon and 3D electrooxidation process. The adsorption capacity was also enhanced. The adsorption capacity of RB 211 on sepiolite was also studied in Alkan et al. (2015), and found similar adsorption capacity for equivalent initial color concentration in higher ionic strength [14].
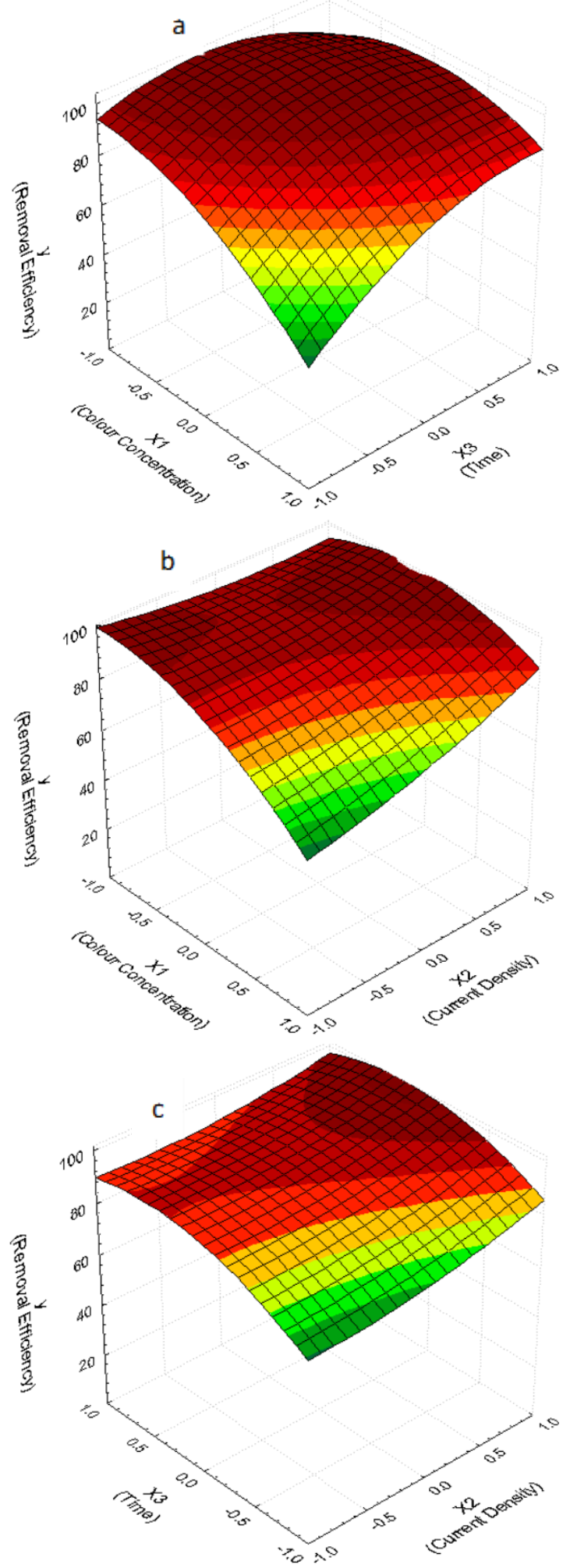

Figure 3. Effect of color concentration, current density and time on decolorization of $\mathrm{RB}$ by $3 \mathrm{D}$-electrooxidation process 


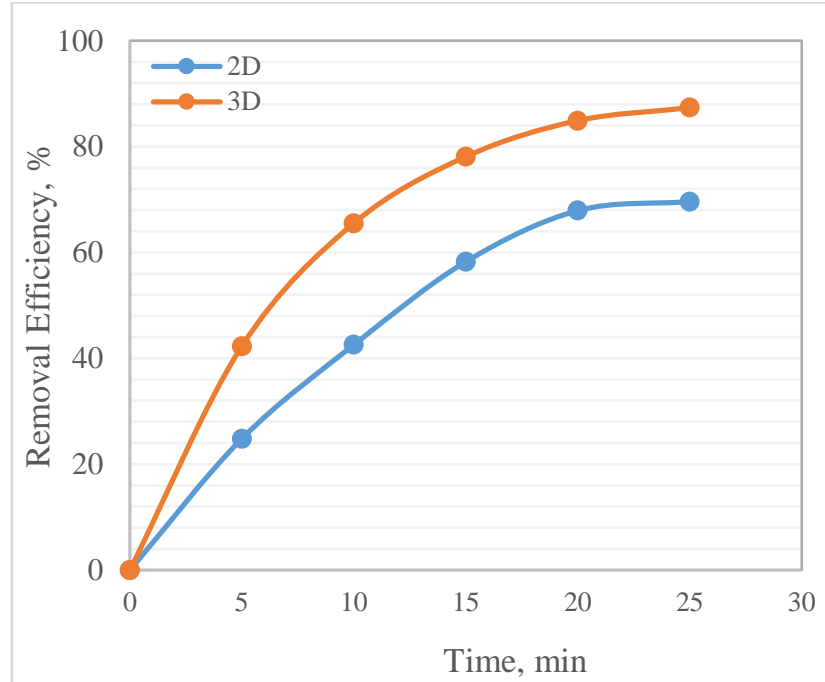

Figure 4. Comparison of $3 \mathrm{D}$ and $2 \mathrm{D}$ electrooxidation processes (Color concentration: 100mg/L, AC Concentration: $0.5 \mathrm{~g} / \mathrm{L}$, Current Density: $20 \mathrm{~mA} / \mathrm{cm}^{2}$ )

Besides, the results are considered for their suitability for adsorption isotherms (Langmuir and Freundlich isotherms) and kinetic modelling (Pseudo-First order and PseudoSecond order kinetics). The results of isotherm and kinetic modelling can be seen in Table 5. According to regression coefficient of isotherms, Langmuir isotherm model was found more suitable. While Freundlich isotherm modelling admits heterogenous energy, Langmuir accepts homogenous energy [15]. According to this information, 3D electrooxidation process is homogenous. When regression coefficients of Pseudo-first-order and Pseudo-second-order kinetic models compared, 3D eletrooxidation process is more suitable for pseudo-second-order kinetic model. The suitability of pseudo-second-order kinetic model was analysed for polynomial (R2: 0.997) and linearized (R2: 0.995 ) indicates that the $3 \mathrm{D}$ process is a chemisorption [15 17]. As Tran et al. (2017) mentioned, advanced analysis techniques should be used to prove whether chemisorption was occurred [18]. Maximum adsorption capacity is found to be $19.095 \mathrm{mg} / \mathrm{g}$.

Table 5. Comparison of isotherms and kinetic modelling

\begin{tabular}{|ccc|}
\hline Model & Parameter & $3 \mathrm{D}$ \\
\hline Freundlich Isoterm & $\mathrm{K}_{\mathrm{F}}$ & 48.194 \\
& $\mathrm{n}$ & -2.170 \\
& $\mathrm{R}^{2}$ & 0.915 \\
\hline Langmuir Isotherm & $\mathrm{q}_{\max }$ & 5.930 \\
\cline { 2 - 3 } & $\mathrm{K}_{\mathrm{L}}$ & 0.337 \\
\cline { 2 - 3 } & $\mathrm{R}^{2}$ & 0.968 \\
\hline Pseudo second-order & $\mathrm{q}_{\mathrm{e}}$ & 19.095 \\
\hline Kinetic & $\mathrm{k}_{2}$ & 0.006 \\
& $\mathrm{R}^{2}$ & 0.995 \\
\hline Pseudo first-order Kinetic & $\mathrm{q}_{\mathrm{e}}$ & 28.874 \\
& $\mathrm{k}_{1}$ & 0.121 \\
\hline & $\mathrm{R}^{2}$ & 0.985 \\
\hline
\end{tabular}

\section{CONCLUSION}

Three-dimensional electrooxidation process was conducted by using activated carbon, and model via Box-Behnken Design. The independent variables were selected as color concentration, current density and time. The ANOVA results and also surface plots of BBD design showed that the most effective parameter was color concentration, followed by time and current density. Color concentration less than 60 $\mathrm{mg} / \mathrm{L}$ can be almost completely degraded in 15 minutes. Optimum conditions showed that $60.6 \mathrm{mg} / \mathrm{L}$ initial color concentration can be removed in $20.5 \mathrm{~min}$ by $20 \mathrm{~mA} / \mathrm{cm}^{2}$ current density and $500 \mathrm{mg} / \mathrm{L}$ AC concentration. When 3D process is compared with $2 \mathrm{D}$ process, the difference on removal efficiency was observed as approximately $19 \%$. This shows that activated carbon acts as a carbocatalyst and as well as adsorbent. Besides, isotherm and kinetic modelling indicated that chemisorption was occurred. Iron, hematite and materials which give Fenton-like reaction in nano-sized should be investigated in $3 \mathrm{D}$ processes to enhance degradation for recalcitrant pollutants.

\section{REFERENCES}

[1] K. Ulucan-Altuntas and F. Ilhan, "Enhancing Biodegradability of Textile Wastewater by Ozonation Processes: Optimization with Response Surface Methodology," Ozone: Science and Engineering, 2018, doi: 10.1080/01919512.2018.1474339.

[2] M. Sarıoğlu Cebeci, S. Selçuk, "Atıksudan Fotokatalitik Yöntemle Boya Giderimi Ve Mineralizasyonu”, Akademik Platform Mühendislik ve Fen Bilimleri Dergisi. Vol. 8(3), pp. 533-539, 2020, doi: 10.21541/apjes.625338

[3] F. Ilhan, K. Yetilmezsoy, A. Kabuk, K. Ulucan, T. Coskun, and B. Akoglu, "Evaluation of operational parameters and its relation on the stoichiometry of Fenton's oxidation to textile wastewater," Chemical Industry and Chemical Engineering Quarterly, 2017, doi: 10.2298/ciceq150907048i.

[4] A. Aygun, B. Eren, Elektrokoagülayon Yöntemiyle Reaktif Yellow 160 Boyar Maddesinin Giderimi. Akademik Platform Mühendislik ve Fen Bilimleri Dergisi. 5(3): 10-18, 2017, doi: 10.21541/apjes.

[5] E. GilPavas, P. Arbeláez-Castaño, J. Medina, and D. A. Acosta, "Combined electrocoagulation and electro-oxidation of industrial textile wastewater treatment in a continuous multi-stage reactor," Water Science and Technology, 2017, doi: 10.2166/wst.2017.415.

[6] A. Deghles and U. Kurt, "Treatment of raw tannery wastewater by electrocoagulation technique: optimization of effective parameters using Taguchi method," Desalination and Water Treatment, 2016, doi: 10.1080/19443994.2015.1074622.

[7] C. Zhang, Y. Jiang, Y. Li, Z. Hu, L. Zhou, and M. Zhou, "Three-dimensional electrochemical process for wastewater treatment: A general review," Chemical Engineering Journal. 2013, doi: 10.1016/j.cej.2013.05.033.

[8] R. Misra, N. N. Neti, D. D. Dionysiou, M. Tandekar, and G. S. Kanade, "Novel integrated carbon particle based three 
dimensional anodes for the electrochemical degradation of reactive dyes," RSC Advances, vol. 5, no. 14, pp. 1079910808, 2015, doi: 10.1039/c4ra13550d.

[9] X. Zhu, J. Ni, X. Xing, H. Li, and Y. Jiang, "Synergies between electrochemical oxidation and activated carbon adsorption in three-dimensional boron-doped diamond anode system," Electrochimica Acta, vol. 56, no. 3, pp. 1270-1274, 2011, doi: 10.1016/j.electacta.2010.10.073.

[10] M. R. Foroughi, M., Rahmani, A. R., Asgari, G., Nematollahi, D., Yetilmezsoy, K. and Samarghandi, "Optimization of a three-dimensional electrochemical system for tetracycline degradation using box-behnken design.," Fresenius Environmental Bulletin, vol. 27, no. 3, pp. 1914-1922, 2018.

[11] F. Lücking, H. Köser, M. Jank, and A. Ritter, "Iron powder, graphite and activated carbon as catalysts for the oxidation of 4-chlorophenol with hydrogen peroxide in aqueous solution," Water Research, 1998, doi: 10.1016/S0043-1354(98)00016-5.

[12] M. H. Zhou and L. C. Lei, "Electrochemical regeneration of activated carbon loaded with p-nitrophenol in a fluidized electrochemical reactor," Electrochimica Acta, vol. 51, no. 21, pp. 4489-4496, 2006, doi: 10.1016/j.electacta.2005.12.028.

[13] E. Andrés García, M. Agulló-Barceló, P. Bond, J. Keller, W. Gernjak, and J. Radjenovic, "Hybrid electrochemical-granular activated carbon system for the treatment of greywater," Chemical Engineering Journal, vol.
352, no. April, pp. 405-411, 2018, doi: 10.1016/j.cej.2018.07.042.

[14] M. Alkan, S. Çelikçcapa, Ö. Demirbaş, and M. Dogan, "Removal of reactive blue 221 and acid blue 62 anionic dyes from aqueous solutions by sepiolite," Dyes and Pigments, 2005, doi: 10.1016/j.dyepig.2004.07.018.

[15] K. Ulucan-Altuntas, E. Debik, C. B. Ustundag, M. D. Guven, and K. A. Gocen, "Effect of visible light on the removal of trichloromethane by graphene oxide," Diamond and Related Materials, p. 107814, 2020, doi: https://doi.org/10.1016/j.diamond.2020.107814.

[16] A. Gunay, B. Ersoy, S. Dikmen, A. Evcin, "Investigation of equilibrium, kinetic, thermodynamic and mechanism of Basic Blue 16 adsorption by montmorillonitic clay", Adsorption, vol.19, pp.757-768, 2013, doi: 10.1007/s10450-013-9509-4

[17] F. Ilhan, K Ulucan-Altuntas, Y. Avsar, U. Kurt, A. Saral, "Electrocoagulation process for the treatment of metal-plating wastewater: Kinetic modeling and energy consumption" Frontiers of Environmental Science \& Engineering, vol. 13(5), pp.73, 2019, doi: 10.1007/s11783019-1152-1

[18] H. N. Tran, S. You, A. Hosseini-Bandegharaei, H. Chao, "Mistakes and inconsistencies regarding adsorption of contaminants from aqueous solutions: A critical review" Water Research, vol:120, pp. 88-116, 2017, doi: 10.1016/j.watres.2017.04.014 